\title{
Correction to: Global reconstruction of twentieth century lake surface water temperature reveals different warming trends depending on the climatic zone
}

\author{
Sebastiano Piccolroaz ${ }^{1,2} \cdot$ R. lestyn Woolway ${ }^{3} \cdot$ Christopher J. Merchant $^{4,5}$ \\ Published online: 15 May 2020 \\ (C) Springer Nature B.V. 2020
}

\section{Correction to: Climatic Change \\ https://doi.org/10.1007/s10584-020-02663-Z}

This article has been updated. The online published PDF contained mistakes in Eqs. 1 and 2. These have been corrected.

\section{Sebastiano Piccolroaz}

sebastiano.piccolroaz@gmail.com

1 Independent Researcher, Trento, Italy

2 Free University of Bolzano, Bolzano, Italy

3 Dundalk Institute of Technology, Dundalk, Ireland

4 Department of Meteorology, University of Reading, Reading, UK

5 National Centre for Earth Observation, University of Reading, Reading, UK 